\title{
Flora das cangas da Serra dos Carajás, Pará, Brasil: Dicranaceae
}

\author{
Flora of the canga of the Serra dos Carajás, Pará, Brazil: Dicranaceae
}

Fúvio Rubens Oliveira-da-Silva ${ }^{1} \&$ Anna Luiza Ilkiu-Borges ${ }^{1,2}$

\begin{abstract}
Resumo
Duas espécies (Holomitrium arboreum e Leucoloma tortellum) de Dicranaceae foram registradas nas áreas de canga na Serra dos Carajás, no estado do Pará, para as quais é apresentada descrição, ilustração e comentários morfológicos.
\end{abstract}

Palavras-chave: Brioflora, FLONA Carajás, musgos, taxonomia.

\begin{abstract}
Two species (Holomitrium arboreum e Leucoloma tortellum) of Dicranaceae were recorded in areas of canga in the Serra dos Carajás, Pará state, including description, illustration and morphologic comments.
\end{abstract}

Key words: Bryoflora, FLONA Carajás, mosses, taxonomy.

\section{Dicranaceae}

Dicranaceae Schimp. reúne 40 gêneros de musgos acrocárpicos (Goffinet et al. 2009), dos quais 15 gêneros com 54 espécies foram registrados no Brasil (Costa \& Peralta 2015). A família é caracterizada por plantas geralmente robustas, filídios com costa larga na base, células da lâmina alongadas de paredes grossas e porosas, células alares frequentemente diferenciadas, caliptra mitrada ou cuculada, peristômio simples com 16 dentes divididos até a metade ou em direção à base (Gradstein et al. 2001; Goffinet et al. 2009). Nas cangas das Serras dos Carajás foi registrada uma espécie de Holomitrium Brid. e uma de Leucoloma Brid.

\section{Chave de identificação dos gêneros de Dicranaceae das cangas da Serra dos Carajás}

1'. Filídios limbados (bordas hialinas com células lineares). Células superiores pluripapilosas

1. Ausência de filídios limbados (elimbados). Células superiores lisas 1. Holomitrium

\section{Holomitrium Brid.}

Existem aproximadamente 15 espécies no Neotrópico e cinco ocorrem no Brasil (Gradstein et al. 2001; Costa \& Peralta 2015). As espécies desse gênero crescem como epífitas em ramos e troncos de árvores, frequentemente no dossel, ocasionalmente crescem sobre rochas e solo (Allen 1990; Gradstein et al. 2001). Esse grupo é identificado pelos filídios crispados ou torcidos em espiral, elimbados, margem distintamente serrilhada, costa estreita e simples, filídios periqueciais longos, células alares bem desenvolvidas, cápsulas eretas e peristômio com dentes não divididos (Allen 1990; Gradstein et al. 2001).
1.1. Holomitrium arboreum Mitt., J. Linn. Soc., Bot. 12: 58. $1869 . \quad$ Fig. 1a-f

Plantas verde-escuras, 6-12 $\mathrm{mm}$ de comprimento. Caulídio ereto, pouco ramificado. Filídios fortemente crispados quando secos, eretoexpandidos quando úmidos, ovalado-lanceolados, base ovalada, estreitando-se para o ápice lanceolado, $2,5-3,5 \times 0,3-0,7 \mathrm{~mm}$, ápice agudo a agudoacuminado, margem serrilhada do meio ao ápice da lâmina, bi-estratificada, costa percurrente. Células do ápice do filí́dios quadradas, 7,5-12,5 $\mu \mathrm{m}$, lisas, estendendo-se ao longo das margens até a região basal, células da base longo-retangulares a lineares, $50-75 \times 7,5-17,5 \mu \mathrm{m}$, porosas, paredes grossas,

\footnotetext{
'Museu Paraense Emílio Goeldi, Av. Magalhães Barata 376, São Braz, 66040-170, Belém, PA, Brasil.

${ }^{2}$ Autor para correspondência: ilkiu-borges@museu-goeldi.br
} 


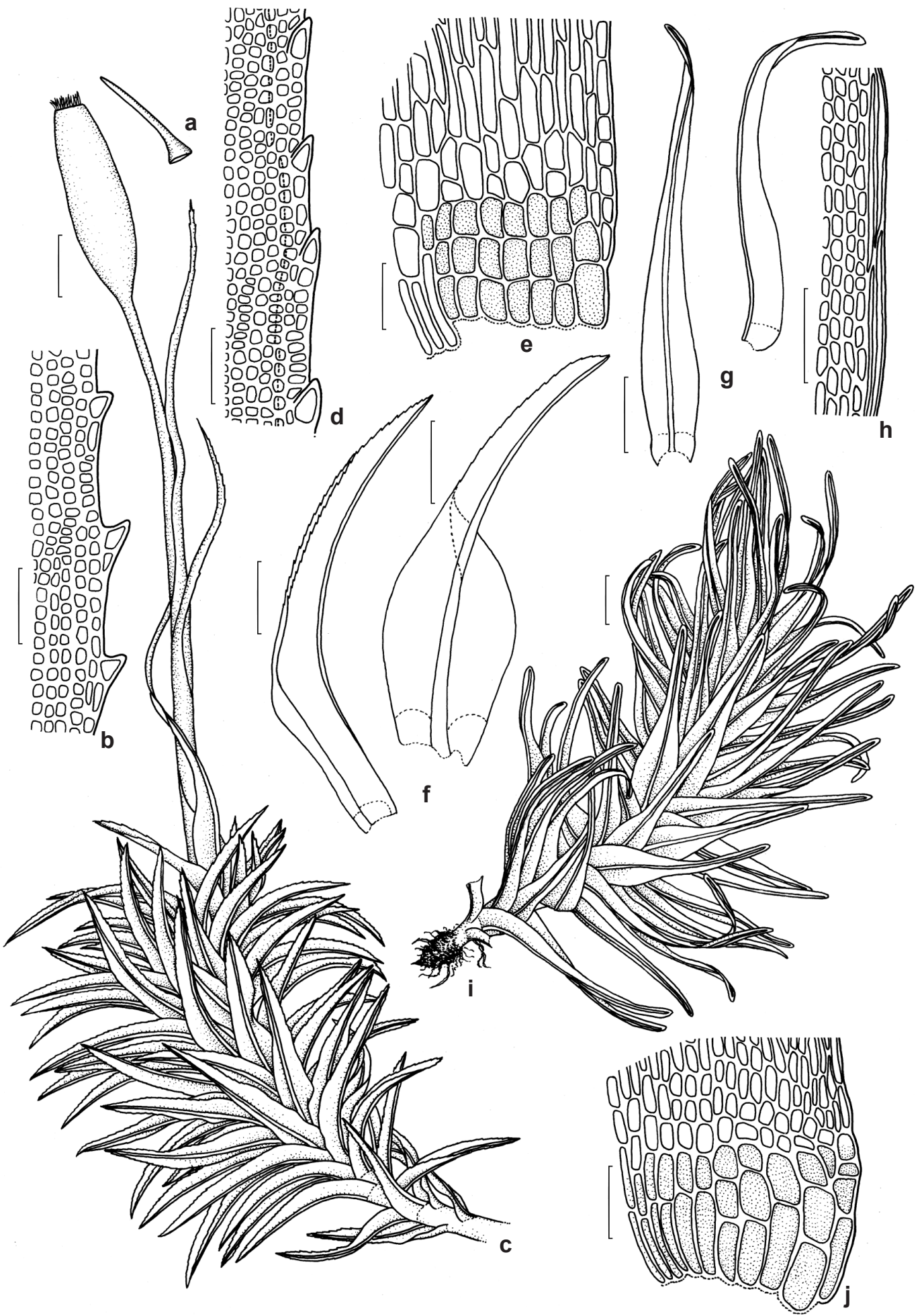

Figura 1 - a-f. Holomitrium arboreum - a. opérculo; b. margem do filídio; c. hábito; d. margem bi-estratificada do filídio; e. base do filídio; f. filídios. g-j. Leucoloma tortellum - g. filídios; h. margem do filídio; i. hábito; j. base do filídio. Barras: a, c $=1000 \mu \mathrm{m} ; \mathrm{b}, \mathrm{d}, \mathrm{e}, \mathrm{h}, \mathrm{j}=50 \mu \mathrm{m} ; \mathrm{f}, \mathrm{g}, \mathrm{i}=500 \mu \mathrm{m}$.

Figure 1 - a-f. Holomitrium arboreum - a. operculum; b. leaf margin; c. habit; d. bi-layered leaf margin; e. leaf base; f. Leaves. g-j. Leucoloma tortellum - g. leaves; h. leaf margin; i. habit; j. leaf base. Bars: a, c $=1000 \mu \mathrm{m} ; \mathrm{b}, \mathrm{d}, \mathrm{e}, \mathrm{h}, \mathrm{j}=50 \mu \mathrm{m} ; \mathrm{f}, \mathrm{g}, \mathrm{i}=500 \mu \mathrm{m}$. 
células alares aumentadas, ovalado-retangulares, 37,5-75 × 20-25 $\mu \mathrm{m}$, de coloração amarelada a alaranjada. Filídios periqueciais lanceolados, 7,2-9,7 $\times 0,3-0,5 \mathrm{~mm}$. Seta ereta, $8-10 \mathrm{~mm}$ de comprimento, cápsula cilíndrica, 2,2-2,7 × 0,7-0,8 mm, dentes do peristômio frágeis, papilosos, perfurados ao longo de uma linha mediana, opérculo com um longo bico, 1,6-2 mm de comprimento, caliptra cuculada, lisa. Material selecionado: Canaã dos Carajás, S11C, 6²2'57,9'S, 50²3'07'W, 29.IV.2015, A.L. Ilkiu-Borges et al. 3476 (MG). Parauapebas, N3, 31.III.1993, C.S. Rosário \& J.S. Ramos 924 (MG).

A espécie é caracterizada pelos filídios fortemente crispados quando secos e eretoexpandidos quando úmidos, células quadradas a sub-quadradas no ápice, longo-retangulares a lineares na base e células alares aumentadas de coloração amarelada ou alaranjada, margem biestratificada e serrilhada do meio ao ápice da lâmina e filídios periqueciais longos, quase do tamanho da seta. Segundo Allen (1990) e Buck (2003), Holomitrium arboreum ocorre principalmente como corticícola e ocasionalmente sobre rochas e solo. Nas cangas da Serra dos Carajás, essa espécie ocorreu sobre rocha em mata baixa e em tronco vivo sobre córrego temporário de drenagem natural.

América Central e América do Sul. No Brasil: AM, BA, PA, PE, RJ, RO, RR e SP. Serra dos Carajás: Serra Norte: N3; Serra Sul: S11C.

\section{Leucoloma Brid.}

Este é um gênero pantropical com centro de distribuição em Madagascar (La Farge 1998). Possui cerca de 12 espécies no Neotrópico, das quais quatro ocorrem no Brasil (Gradstein et al. 2001; Costa \& Peralta 2015). As espécies deste gênero crescem como epífitas, ocasionalmente sobre troncos em decomposição e rochas (Gradstein et al. 2001). Se caracterizam pelas plantas contorcidas quando secas, filídios limbados, borda hialina com células lineares, costa estreita e simples, células do ápice curtas e pluripapilosas, células alares bem diferenciadas, podendo ser aumentadas ou retangulares (La Farge 1998; Gradstein et al. 2001; Buck 2003).

2.1. Leucoloma tortellum (Mitt.) A. Jaeger, Ber. Thatigk. St. Gallischen Naturwiss. Ges. 1870-1871: 413. 1872.

Poecilophyllum tortellum Mitt. Journal of the Linnean Society, Botany 12: 94. 1869. Fig. 1g-j

Plantas verde-claras a amarronzadas, 6-10 $\mathrm{mm}$ de comprimento. Caulídio ereto, pouco ramificado, crescendo em tufos frouxos ou dispersos. Filídios fortemente crispados quando secos, ereto-expandidos quando úmidos, oblongolanceolados, base oblongo-ovalada, estreitando-se para o ápice lanceolado, 1,8-3,5 × 0,2-0,4 mm, ápice subagudo a obtuso, densamente papiloso, margem inteira, formada por duas fileiras de células hialinas e lineares, costa sub-percurrente a percurrente, obscurecidas pelas papilas. Células do ápice do filídios sub-quadradas a arredondadas, 2,5-5 $\mu \mathrm{m}$, densamente pluripapilosas, células da base sub-retangulares, 25-50 × 5-10 mm $\mu \mathrm{m}$, lisas, células alares infladas, retangulares, 37,5-87,5 × 15-25 mm, de coloração amarelada a alaranjada.

Material selecionado: Canaã dos Carajás, Serra do Tarzan, 6¹9'49'S, 5007'53,8'W, 01.IX.2015, A.L. Ilkiu-Borges et al. 3677 (MG). Parauapebas, N3, 24.X.1992, C.S. Rosário \& J.S. Ramos 2070 (MG).

A espécie é identificada principalmente pelas células superiores densamente pluripapilosas e a margem inteira, formada por duas fileiras de células hialinas e lineares. Nas cangas da Serra dos Carajás, essa espécie ocorreu sobre rocha de ferro em canga aberta e em mata baixa sobre canga.

América Central e América do Sul. No Brasil: AM, CE, MG, PA, RO e RR. Serra dos Carajás: Serra Norte: N3; Serra Sul: Serra do Tarzan.

\section{Agradecimentos}

Agradecemos ao Museu Paraense Emílio Goeldi e Instituto Tecnológico Vale, a infraestrutura e demais apoios fundamentais para o desenvolvimento deste trabalho, assim como à Dra. Ana Maria Giulietti Harley e ao Dr. Pedro Viana, coordenadores do projeto conveniado MPEG/ITV/ FADESP (01205.000250/2014-10) e ao projeto aprovado pelo CNPq (processo 455505/2014-4), o financiamento; ao ICMBio, em especial ao biólogo Frederico Drumond Martins, a licença de coleta concedida e suporte nos trabalhos de campo; ao CNPq, a bolsa de Mestrado concedida ao primeiro autor e a bolsa de Produtividade em Pesquisa concedida à segunda autora.

\section{Referências}

Allen BH (1990) A prelimintary treatment of the Holomitrium complex (Dicranceae) in the Central America. Tropical Bryology 3: 59-71.

Buck WR (2003) Guide to the plants of Central French Guiana. Part 3. Mosses. Memoirs of The New York Botanical Garden 76: 1-167.

Costa DP \& Peralta DF (2015) Bryophytes diversity in Brazil. Rodriguésia 66: 1063-1071. 
Goffinet B, Buck WR \& Shaw AJ (2009) Morphology and classification of the bryophyta. In: Goffinet B \& Shaw AJ (eds.) Bryophyte Biology. Cambridge University Press, Cambridge. Pp. 55-138.

Gradstein SR, Churchill SP \& Salazar-Allen N (2001) Guide to the bryophytes of Tropical America.
Memoirs of the New York Botanical Garden 86: $1-577$.

La Farge C (1998) The infrageneric phylogeny, classification, and phytogeography of Leucoloma (Dicranaceae, Bryopsida). The Bryologist 101: $181-220$.

\section{Lista de exsicatas}

Ilkiu-Borges AL et al. 3476 (1.1), 3677 (2.1), 3488 (1.1). Rosário CS \& Ramos JS 924 (1.1), 2043 (2.1), 2065 (2.1), 2066 (2.1), 2070 (2.1).

Editor de área: Dr. Alexandre Salino Artigo recebido em 10/11/2017. Aceito para publicação em 08/01/2018. This is an open-access article distributed under the terms of the Creative Commons Attribution License. 